\title{
Socio-Cultural Potential of a Scientific Library of Higher Education Institution in Students' Value Attitude to Education Development
}

\author{
Alsu R. Rakhmanova ${ }^{1}$, Victoria V. Sadovaya ${ }^{2} \&$ Marina Yu. Denisova ${ }^{2}$ \\ ${ }^{1}$ Yelabuga Institute of Kazan (Volga region) Federal University, Russia \\ ${ }^{2}$ Kazan (Volga region) Federal University, Russia \\ Correspondence: Alsu Ramilevna Rakhmanova, Department of Pedagogic, Yelabuga Institute of Kazan (Volga \\ region) Federal University, Kazan, 423600, Russia. E-mail: rahmanovaar@mail.ru
}

\author{
Received: September 23, 2014 Accepted: October 10, $2014 \quad$ Online Published: December 2, 2014 \\ doi:10.5539/ass.v11n1p176 \\ URL: http://dx.doi.org/10.5539/ass.v11n1p176
}

\begin{abstract}
The article is aimed to identify social-cultural potential of a scientific library of higher education institution in students' value attitude to education development, and also to reveal the content and technology of students' involvement in its activity. With reference to the specified goals, the main approach to this issue research has been the social-cultural approach that determines the efficiency of applied problems solutions in the process of students' value attitude to education development in the context of a scientific library of higher education institution. In the article there has been revealed the specifics of social-cultural activity of a scientific library aimed at the formation of students' value attitude to education; there has been presented the complex of task-oriented and systematic pedagogical impacts on personality consciousness and behavior via involving tem in social-cultural forms of work of a scientific library in the process of which there takes place the development of students' value attitude to education. Materials of this article can be useful for teachers to develop students' value attitude not only to education but to scientific-research activity as well; to researchers who deal with the subject of personality value attitude development.
\end{abstract}

Keywords: value attitude, social-cultural activity, social-cultural contexts, scientific library of higher education institution, involvement of students

\section{Introduction}

The present-day situation is characterized by the existence of goal sets aimed at the development of a free, social-responsible, socially-useful, creative person and incongruous real value orientations of various social groups. The research of the system of values and their formation are an important task of pedagogy of social-cultural activity; specification of their essence, content and features formation for modern conditions of the society is timely and perspective (Ryseva, 2014; Khairullina, 2007). The process of value formation is of particular significance for students who make one of capable forces of a society and on whom the prospect of this society development_depends (Salimova, 2011; Al-Kahtani \&Allam, 2013; Stepanova, 2009).

The activity of scientific libraries of higher education institution aimed at students' value attitude to education development should be singled out as one of the directions; their opportunities have significantly increased due to the introduction of new telecommunication and information technologies in their activity (Stepanova, 2009). The main parameters of scientific libraries activity are connected with the quality improvement of education on the basis of quality management system and information technologies introduction in all spheres of higher education institution activity, change of higher education institution structure, etc. Unfortunately, complex researches of scientific library of higher education institution activity aimed to develop students' value attitude to education in the context of higher professional education transformation have not been carried out so far.

The importance of the research is also determined by the necessity of modern Russian society to find new approaches, forms and methods to arrange special cultural-leisure activity of scientific library aimed at the formation of education values. Therefore the development of students' value attitude to education in the course of their participation in social-cultural activity of a scientific library of higher education institution is a topical issue (Salimova, 2012; Kovalenko, 2011; Mbagwu \& Akanwa, 2012). 
Besides, the relevance of the research subject concerning a scientific library of higher education institution as a social-cultural institution is defined by:

- the necessity to study new structural elements of a scientific library which have appeared as a result of its social-upbringing functions expansion;

- the necessity to analyze, forecast and explain the processes of a scientific library and pedagogical community interaction aimed at the formation of students' value attitude to education;

- the understanding of social-cultural functions of a scientific library aimed to provide students' value attitude to education (Salimova, 2006);

- the influence of a scientific library on the formation of students' value attitude to education and self-determination according to the tendencies of social-cultural development of the country.

\section{Materials and Methods}

Experimental work was based on the following common didactic principles: conformity to natural laws, consciousness, activity, illustrativeness, systematicity, consistency, scientific character, accessibility; combination of theory with practice; holistic approach to the development of goals, tasks, structures, functions of an educational institution, and also contents, forms and methods of teaching and upbringing activity; contents and forms variability of a modelled educational environment of an institution.

Pilot-experimental work was carried out from 2007 to 2011 on the educational base of the faculty of economy and management of FSAEI "Kazan (Volga) Federal university" and its branches. 543 persons participated in the experiment.

The aim of the stating experiment was to define the levels of the development of students' value attitude to education in the course of their participation in the activity of a scientific library of higher education institution. At the stating stage of the experiment there was studied the condition of teaching and upbringing process and plans of higher education institution curators' work to define the place and role of education values in the system of interaction of educational process subjects: teachers, library workers and students. There were also observed students' extracurricular activities.

Eight values (I.G. Senin's questionnaire of terminal values) are singled out in the studied scientific literature. According to the results of diagnostics we have revealed values students give preference to: high financial position (93\%), one's own prestige (69\%); the value of self-development is less significant for them (35\%), the value of one's own identity development is $54 \%$. However, in order to reach high financial position, to have prestige, students did not single out the importance of value attitude to education.

In the course of the stating experiment we applied diagnostic techniques to identify the initial level of students' value attitude to education by finding average figures of assigned values. When diagnosing, we applied the following techniques: method of conversation, questioning and supervision, V. Smekal and M. Kuchera's technique "Personality orientation", Yu.M. Bludov and V.A. Plakhtiyenko's self-assessment technique, T.I. Ilyina's technique "Motivation for studying at a higher education institution", and Yu.M. Yurlov's technique "Communication needs" (Best psychological tests for professional selection and career counseling, 1992). According to the obtained data, $64 \%$ of students have a minimum level of education values development, $21 \%$ of students have a medial level of education values development and only $15 \%$ of students possess a maximum level of studied values development. The results of the stating stage of the experiment allow to draw a conclusion that students' value attitude development to education is carried out insufficiently.

We have realized programs according to the directions of social-cultural activity of a scientific library of higher education institution: intellectual direction: "A thousand of wise pages", professional direction: "Successful start into a profession" and "A professional", spiritual-moral direction: "The soul is getting hard without kind books".

To implement the program of the intellectual direction we arranged some activities separately for students of junior and senior courses. They were involved in the work of the clubs "A clever Book", "An owl", "Experts". This activity promoted the development of educative dialogue, knowledge, scientific search value. We used the following forms and methods of work: excursions, collective trips to institutions of culture, meetings with famous scientists, writers, artists, historians of the Republic of Tatarstan. We carried out trainings aimed at the development of pair, group and collective work skills. They were based on the knowledge obtained as a result of students' study of educational subjects, psychology-pedagogical training of intellectual emotions and feelings development, observancy, experience which they got in the process of tasks implementation that provided the revision of previously studied material. 
Within the frames of carried-out work, we tested a psychology-pedagogical training aimed at the development of students' intellectual emotions and feelings on the basis of general observancy; the following provisions made the foundation of it: fundamental condition of students' positive emotions development is their awareness of the necessity to transform their inner world and search of opportunities for self-realization in the process of training, i.e. the development of self-assessment, interest, emotionality. ("Advertising", "Reframing", "We", etc.). These trainings enriched students with knowledge about emotional states and their influence on surrounding persons, promoted the development of observancy, thinking, reflection skills and control over their emotions.

To implement the program of the professional direction we conducted a number of classes which promoted the formation of value attitude to cognition and scientific search as the development of such criteria as cognitive need, needs for self-realization and motives corresponding to them, namely, the importance of a subject for vocational training, interest to a specific discipline of studying, arising difficulties of mastering this subject, etc. were of great attention.

As the pilot study showed, the staff of the scientific library provided favorable influence of high education institution upbringing system on an individuality that is realized due to the following functions: individualizations of students' perception of an environmental surrounding (real social and virtual computer); individualization of student's activity; pedagogical help for educational problems solutions and, as a result, correctional influence; diagnosing of personality individual development. In the course of studies a student interacts not with one teacher but a group of teachers and students. The joint, coordinated activity of academic teaching staff is the most effective and contributes sufficiently to student's identity formation.

At the same time with the introduction of new information technologies and forms of teaching, the list of tasks of higher school libraries has considerably increased. The service of various categories of users has become more differentiated. The use of websites and electronic libraries expands information service opportunities. During the experiment we paid special attention to the culture of scientific information search on the Internet. However, the problem of information accessibility for students that influence the formation of their value attitude to education still remains relevant.

The strategy of a scientific library is inseparable from the strategy of a higher education institution and it makes a part of it. Thus, there are goals and tasks which the scientific library can and has to establish. It concerns the increase of electronic documents in a general funds array; establishing of a uniform approach for the acquisition of funds; interaction and consultations with chairs at the time of fund acquisition and information resources choice to coordinate efforts to increase the level of students' computer literacy in the sphere of library programs use and means of effective information search. In particular, we have developed a complex of measures which would allow students to master search tools of automated library information system and Internet, and also to increase the efficiency of search of reliable information necessary for them in other different sources. So it is possible to say that it is the issue concerning the participation of high academic library in the development of students' information competencies.

To implement the program of a spiritual-moral direction we tested and endorsed conversations promoting empathy, "immersion" of students in the atmosphere of emotions, moral. ("Story, fairy tale, parable, metaphor ...", "Culture of behaviour", "Happiness recipes", etc.). Literary salon "Green Lamp" was organized by teachers and library workers for undergraduates where all participants have an opportunity to listen and read poetry. Exhibitions of artists - friends of higher education institution were organized by the staff of a scientific library of higher education institution to which students of undergraduate courses, creative elite and representatives of government and clergy were invited.

\section{Results}

The complex of performed events promoted the development of skills to present the material clearly and accurately, to conduct conversation correctly, to ask questions, to develop listening skills, skills to hear and understand the interlocutor. The efficiency of this cycle of lectures is confirmed by the fact that students' need in communication and the necessity to come independently into new business and friendly contacts essential for self-development and self-education, to show "the individual self" have increased.

The experiment showed that in the course of social-cultural work of a scientific library of higher education institution students underwent significant changes in their value attitude to education. The complex of considered levels of educational dialogue value indicators development, knowledge value and value of scientific search give us a chance to define the level of students' value attitude to education development by finding average figures of singled out values. 
The control sample of the experiment was carried out to identify the dynamics of levels of students' value attitude to education development (fig. 1). The application technique at the control stage was similar to the technique at the stating stage of the experiment.

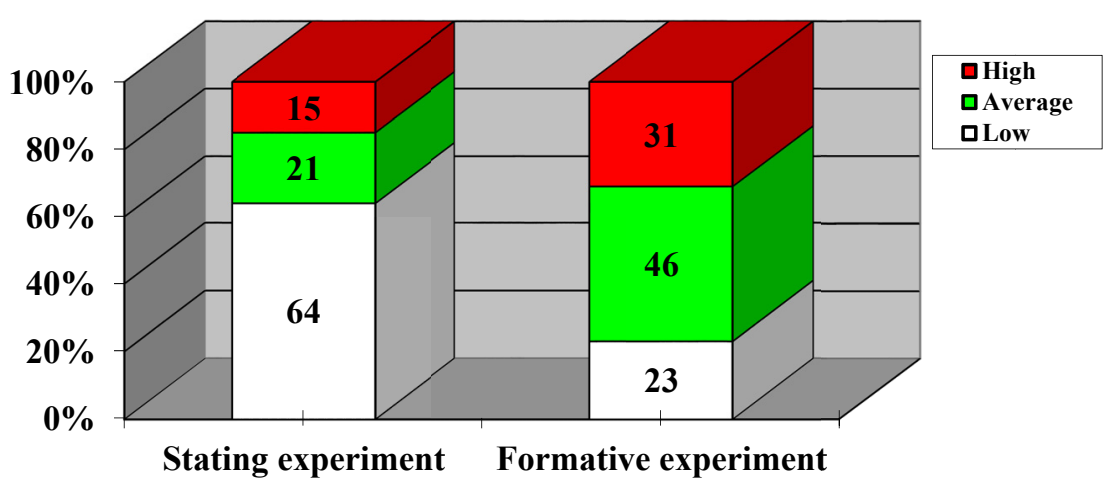

Figure 1. Comparative results of levels of students' value attitude to education development

Having generalized the obtained data and compared average figures of levels of students' value attitude to education development in the process of their participation in social-cultural activity of a scientific library, we specified that the number of students who reached a high level (by 14\%) considerably increased in the experimental group in comparison with the control one, and the number of students with a low level of education values development (by $32 \%$ ) decreased noticeably (see fig. 2).

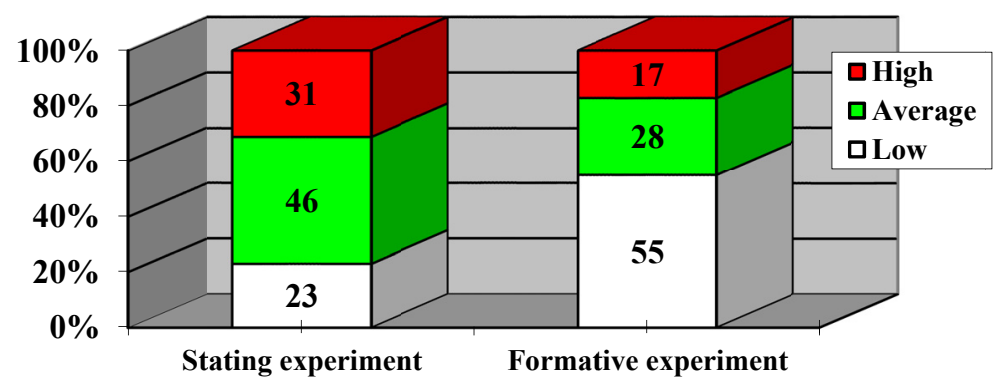

Figure 2. Comparative indicators of levels of students' value attitude to education (control experiment)

Significant improvement of the results in the experimental group and relative stability in the control group testify to the efficiency of work carried out. The achievement of a high rate of obtained results was provided with the integral system of conditions developed by us.

Statistical research of data obtained during the experiment shows that there have taken place significant changes due to the work carried out with students according to all studied parameters in total. The implementation of pedagogical activity aimed at students' value attitude to education formation resulted in the increase of the level of education significance, students estimated the need for interaction, self-assessment, education; they understood the importance of motives for scientific activity.

\section{Conclusions}

Thus, in the course of the research we have revealed the specifics of social-cultural activity of a scientific library of higher education institution aimed at the development of students' value attitude to education; they include the integration of traditional technologies of library work (excursion around the library, information reviews, reviews of scientific publications in magazines, exhibitions of new books) and directions of social-cultural activity according to various programs (intellectual: "A thousand of wise pages"; professional: business club for 
first-year students "Successful start in a profession" and club for undergraduates "A professional"; spiritual-moral: "The soul is getting hard without kind books".

Among indicators that allow to estimate the efficiency of a social-cultural activity of a scientific library of higher education institution in the process of students' value attitude to education development, the following ones have been singled out: values of an educational dialogue, knowledge values, values of scientific search. The value of an educational dialogue is caused by students' need in subject - object-subject interaction; the cognition value is defined by the significance of system knowledge in the course of educational cognitive activity; the value of scientific search is connected with the awareness that scientific-research skills will be necessary in future professional practice.

The following social-cultural conditions promote the effective formation of students' value attitude to education in the activity of scientific library of higher education institution: availability of teachers and library workers that have been trained to arrange social-cultural activity in a scientific library of higher education institution; the impact on students' value attitude to education by means of intellectual, professional and spiritual-moral activity of a scientific library of higher education institution; the arrangement of social-cultural activity of a scientific library of higher education institution.

\section{References}

Al-Kahtani, N. S., \& Allam, Z. (2013). Exploring Value Preferences among Students: An Empirical Study of Salman bin Abdulaziz University. Journal of American Science, 9(12), 44-53.

Khairullina, E. R. (2007). Orientation of students to self-development of core competencies in the design and creative activity. Science and Education Journal, 7.

Kovalenko, O. O. (2011). Socio-cultural space in the library and intellectual aesthetic education of children of $5-8$ years (Thesis $\mathrm{PhD})$. Moscow.

Mbagwu, F., \& Akanwa, P. C. (2012). Constraints To Effective Management Of Secondary School Libraries: A Case Study Of 2 Private And 2 Public Schools In Owerri Municipal L.G.A, Imo State Nigeria. Report and Opinion, 4(2), 13-17.

Ryseva, J. V., Kalashnikova, M. M., Baklanov, P. A., \& Zhdanov, D. O. (2014). Research Experience of the Creative Standpoint Formation of the Novice Comprehensive Secondary School Teacher in Lifelong Vocational Training. Asian Social Science, 10(20).

Salimova, A. R. (2006). Modern trends in the organization of the library. Actual problems of modern pedagogy: Proceedings of the seminar for young scientists (pp. 13-19). Moscow.

Salimova, A. R. (2011). Formation of socio-cultural values of students in the scientific library of the university. Kazan Science, 9, 42-50.

Salimova, A. R. (2012). Socio-cultural activities of the university library as a valuable factor in the formation of students' attitudes to education. Kazan Science, 1, 29-37.

Stepanova, T. P. (2009a). Leisure communication as a factor of cultural meaning consolidation. Bulletin of the Moscow State University of Culture and Arts, 2, 153-156.

Stepanova, T. P. (2009b). Leisure communication: Cross-cultural aspects of interaction. World of Science, Culture and Education, 4(16), 225-227.

\section{Copyrights}

Copyright for this article is retained by the author(s), with first publication rights granted to the journal.

This is an open-access article distributed under the terms and conditions of the Creative Commons Attribution license (http://creativecommons.org/licenses/by/3.0/). 